\title{
The introduction of auto-enrolment and personal accounts to the UK in 2012
}

Received (in revised form): 19th September, 2008

\section{Chris Curry}

joined the Pensions Policy Institute (PPI) as Research Director in July 2002, from the Association of British Insurers where he had been Senior Economist. Before this, he was an economic adviser at the Department of Social Security (now the Department for Work and Pensions). At the PPI, he has overseen development of the PPI's unique pensions-modelling capability, and has authored and presented a number of research reports analysing pensions (both state and private), pension reform and personal accounts.

\begin{abstract}
This paper is based on a presentation given to the 2008 Pension Plan Financial Risk Conference in London on 30th April, 2008. More extensive details of the analysis of the issues surrounding the suitability of auto-enrolment into personal accounts can be found in PPI (2006) Are personal accounts suitable for all?, and more details of the analysis of levelling down in PPI (2007) Will personal accounts increase pension saving?, both available to download free of charge from www.pensionspolicyinstitute.org.uk
\end{abstract}

Pensions (2008) 13, 237-245. doi:10.1057/pm.2008.31

Keywords: UK pension reform, auto-enrolment, incentives to save, employer pensions

\section{Introduction}

The pension system in the UK is complex. The foundations of the UK pension system were laid in the 1940s. Since the 1960s, successive governments have changed both the state and private pension elements.

The UK system can be described in the classic multi-tier framework. As it stands today, the UK pensions system has three tiers (Figure 1):

- Tier 1 is provided by the state and consists of a basic level of pension provision to which everyone either contributes or has access, providing a minimum level of retirement income.

- Tier 2 is also provided by the state and aims to provide further pension that is more closely related to employees' earnings levels. Tier 2 has less redistribution (from rich to poor) than Tier 1.Tier 1 and Tier 2 operate on an unfunded 'pay-as-you-go' contributory basis, through the National Insurance (NI) system.

Correspondence: Chris Curry, Pensions Policy Institute, King's College, 26 Drury Lane, 3rd Floor, Room 311, London WC2B 5RL, UK.

E-mail: chris@pensionspolicyinstitute.org.uk
- Tier 3 is private pensions provision, namely all those voluntary pension arrangements that are not directly funded by the state. Private pension contributions, from the employer and/or the individual, fund designated pensions for the individual. The primary aim of private pensions is to redistribute income across an individual's lifetime, and not to redistribute income from higher-income to lower-income people.

On the advice of an independent advisory group called the Pensions Commission, the UK Government has in recent years been undertaking a wide-ranging package of reforms for both state and private pensions.

The most recent reforms, currently passing through Parliament and expected to pass into UK law later in 2008, are aimed at increasing voluntary saving for retirement. The Government aims to do this through measures designed to overcome the inertia that is often cited as a barrier to employees joining work-based pension schemes, ${ }^{1}$ increasing the incentives available to individuals saving in pensions, and widening access to workers whose employer 
does not offer a work-based pension scheme (see Figure 2).

If enacted, the reforms will require all employers to automatically enrol their employees into a personal account (a new type of individual pension account, initially arranged through an employer) or into an existing good pension scheme. Employees will contribute 4 per cent of a band of their earnings and, unless the employee opts out, employers will be compelled to contribute a minimum of 3 per cent. The

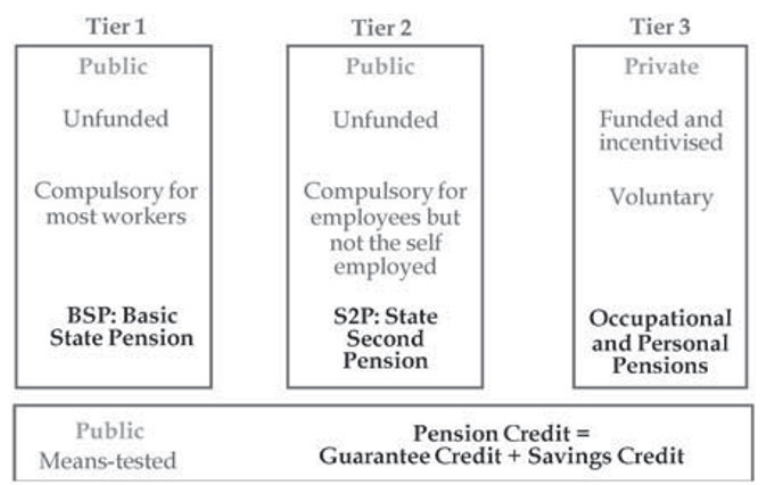

Figure 1: The current UK pension system
Government will contribute at least a further 1 per cent in the form of tax relief. If the employer does not have a scheme that can take these contributions, individuals will (through the employer) be auto-enrolled into a new national pension scheme, currently known as personal accounts.

Figure 3 illustrates how the changes likely to come into place under the proposed pension reforms will change the UK pension system. It includes an additional tier:

- Tier $2 \frac{1}{2}$ will be a public-private partnership of individualised pension provision. This will operate similarly to Tier 3 , private provision, but will be funded through employee, employer and Government contributions.

The question is whether these reforms will deliver the increase in retirement saving they set out to achieve? The Pensions Policy Institute (PPI), an independent research institute, has analysed the impact that the Government's reforms are likely to have and identified the

Overcoming inertia: Auto-enrolment for eligible employees

- The Government has proposed that individuals will be automatically enrolled into qualifying work-based pension schemes or personal accounts if they are workers (employees) aged between 22 and state pension age, and earning above approximately $£ 5,000$ a year.

- Employees who earn below £5,000 a year or who are aged under 22 or over state pension age will not be eligible for auto-enrolment, and neither will the self-employed or non-workers. These people will be able to choose to join personal accounts on a voluntary opt-in basis in certain circumstances.

Increasing incentives: Employer contribution and Government tax relief

- The Government has proposed that contributions will be made on a band of earnings by those earning between around $£ 5,000$ and $£ 33,500$ a year, the personal accounts earnings band, which will be uprated in line with earnings.

- There will be a minimum combined contribution level of 8 per cent of band earnings for employees. This will comprise 4 per cent from the individual, a minimum of 3 per cent from the employer and at least 1 per cent from the state through tax relief.

- Contributions will be phased in over three years, at 1, 3 and then 5 per cent for individuals (including tax relief); and 1,2 and then 3 per cent for employers.

- Employees aged below 22 could choose to opt in to personal accounts on a voluntary basis and receive an employer contribution. Employees earning less than $£ 5,000$ a year could also choose to opt in and would receive tax relief on their savings, but there will be no requirement for an employer contribution to be payable.

Widening access: Introduction of the personal accounts scheme

- The Government proposes to introduce low cost personal accounts to give those without access to occupational pension schemes the opportunity to save. A key part of this is a low charge, expected to be equivalent to an annual management charge of 0.5 per cent.

- The personal accounts scheme is a national scheme that is targeted at moderate to low earners without access to good pension provision. It will be an individual pension account, although the initial arranging of the account will be through the employer.

Figure 2: The Government's reform proposals 


\begin{tabular}{|c|c|c|c|}
\hline Tier 1 & Tier 2 & Tier $2^{1} \frac{1}{2}$ & Tier 3 \\
\hline Public & Public & Public-Private & Private \\
\hline Unfunded & Unfunded & $\begin{array}{l}\text { Funded and } \\
\text { incentivised }\end{array}$ & $\begin{array}{l}\text { Funded and } \\
\text { incentivised }\end{array}$ \\
\hline $\begin{array}{l}\text { Compulsory for } \\
\text { most workers }\end{array}$ & $\begin{array}{l}\text { Compulsory for } \\
\text { employees but } \\
\text { not the self } \\
\text { employed }\end{array}$ & $\begin{array}{c}\text { Compulsory for } \\
\text { employer if } \\
\text { employee does } \\
\text { not opt out }\end{array}$ & Voluntary \\
\hline $\begin{array}{l}\text { BSP: Basic } \\
\text { State Pension }\end{array}$ & $\begin{array}{l}\text { S2P: State } \\
\text { Second } \\
\text { Pension }\end{array}$ & $\begin{array}{l}\text { Personal } \\
\text { accounts }\end{array}$ & $\begin{array}{l}\text { Occupational } \\
\text { and personal } \\
\text { pensions }\end{array}$ \\
\hline $\begin{array}{c}\text { Public } \\
\text { Means-tested }\end{array}$ & \multicolumn{3}{|c|}{$\begin{array}{c}\text { Pension Credit }= \\
\text { Guarantee Credit + Savings Credit }\end{array}$} \\
\hline
\end{tabular}

Figure 3: The (proposed) reformed UK pension system

challenges for the Government as the Pensions Bill continues to make its way through Parliament.

\section{The reforms have broad support, but there are some concerns}

The Government's proposals largely conform to the template set out by the Pensions Commission and have commanded a fairly wide degree of consensus. Employer bodies, unions, consumer groups and the main opposition parties have stood behind the broad framework of the reforms. These organisations recognise that something needs to be done to encourage more people to save for their retirement. The ongoing debate in Parliament has, however, revealed that, while there may be broad agreement on the general principle and direction of the reforms, there are significant concerns and differences of opinion about how workable the Government's reforms really are and what overall impact they might have.

Two major concerns have been expressed. The first is whether it will pay for people to save in a pension due to the interaction of the new system with means-tested benefits. The second is the possible negative impact that auto-enrolment could have on the existing pension market if employers reduce the generosity of their existing pensions in response to the increased costs from auto-enrolment. This is often referred to as the risk of 'levelling-down'. Views differ as to the significance of these two issues. The Government generally takes a more sanguine view than the opposition parties or the pensions industry.

\section{Is auto-enrolment suitable for all?}

Auto-enrolment, whether into personal accounts or an equivalent employers scheme, could give many people access to a low-cost pension savings product with an employer contribution for the first time. As a result of the low charges and employer contribution, incomes from saving in personal accounts are likely to be higher than incomes from saving in existing individual pension products for many people.

Inevitably, auto-enrolment raises questions about the suitability of auto-enrolling individuals into personal accounts for all employees, regardless of their circumstances or characteristics. In PPI research, personal accounts are defined as being 'suitable' if individuals do not lose out as a result of their saving. This is a less stringent definition than ensuring that saving in personal accounts is the right thing for all consumers, which would be more consistent with the definition of 'suitability' used by the Financial Services Authority, the UK regulator for individual savings products.

PPI research categorises individuals as being at low risk, medium risk or high risk of autoenrolment into personal accounts that are unsuitable for them, depending on the effective level of return that they are likely to receive.

This concentration on the level of return that individuals receive is a simplification. No single definition of 'suitability' is likely to be appropriate for the circumstances of every individual. For some people, it may be rational to save even if they have a low return on their saving, for example if they have a strong preference for smooth consumption over their lifetime. On the other hand, some people may require a high return, for example if they are very risk-averse or have high levels of debt. Looking at the effective rate of return can, however, be helpful in identifying broad groups of people who may be more at risk of not getting good value from auto-enrolled saving than other groups.

People at low risk of saving in personal accounts that are unsuitable for them are likely to 


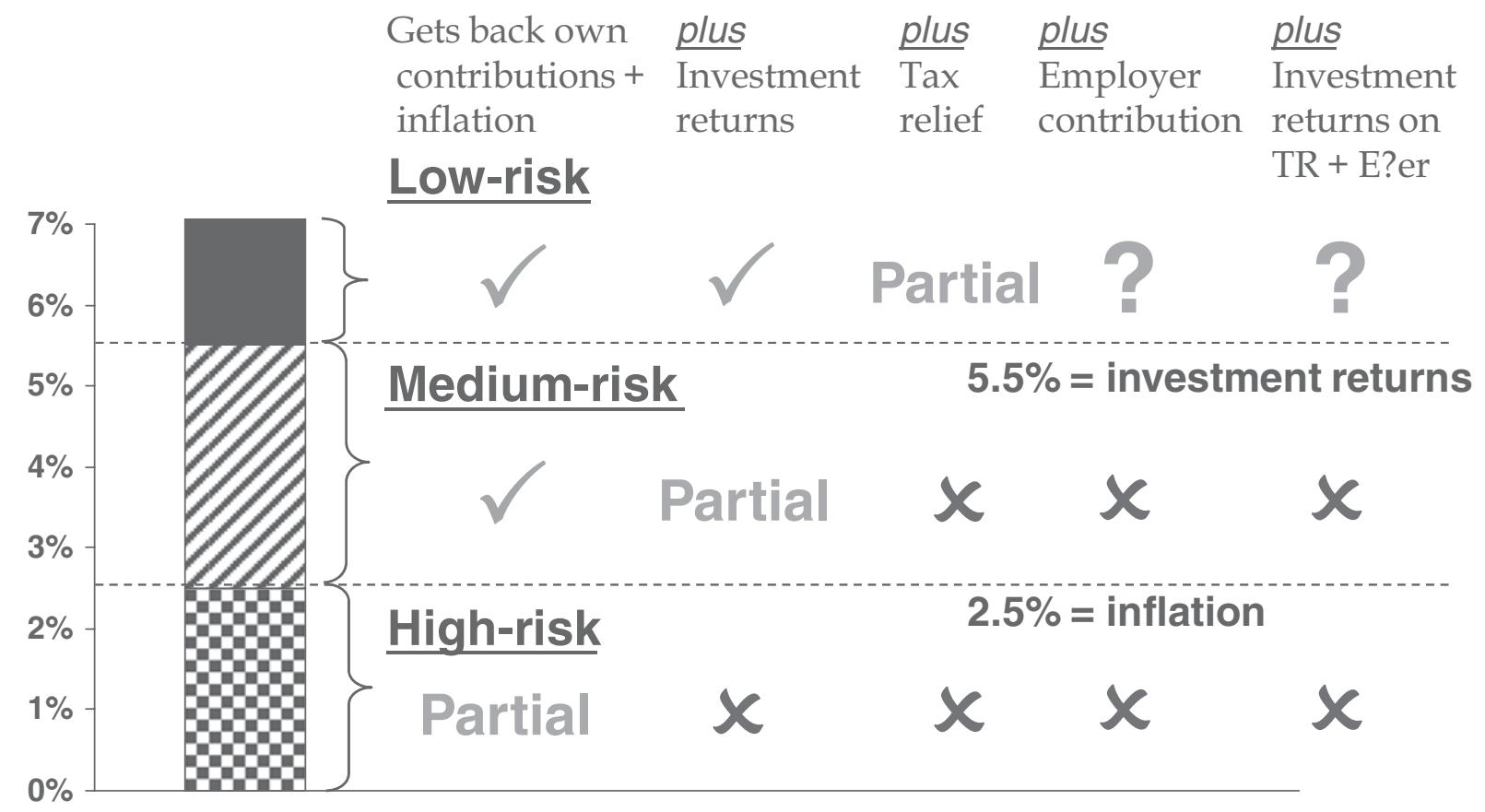

Figure 4: Three risk categories are used, based on the IRR

receive back the value of their individual contributions to personal accounts, together with a full investment return on their contributions (Figure 4). The following are some examples:

- Single people in their 20s in 2012 with full working histories.

- Single men in their 40s and 50s in 2012 who have a full working history and large additional savings.

People at medium risk of saving in personal accounts that are unsuitable for them would receive back the value of their individual contributions, protected for inflation, and some investment returns on their contributions, although they may not receive full credit for the investment returns. This group includes the following:

- Single people in their 20s in 2012 with low earnings and broken working histories, whether because of caring breaks or unemployment.

- Single people in their 40s and 50s in 2012 with low earnings and full working histories.
- Single people in their 20s in 2012 who stay opted in to personal accounts while employed, and then become self-employed at a later date.

People at high risk of saving in personal accounts that are unsuitable for them are likely to receive back less than the value of their contributions into personal accounts. This group includes the following:

- Single people who are likely to rent in retirement and have no additional savings.

- Although they would not be auto-enrolled, single people in their 40s and 50s in 2012 on low to medium incomes who are self-employed.

Other factors can affect whether or not saving into personal accounts is suitable:

- Returns from saving in personal accounts could be higher for people who are married at some point in retirement, rather than always single as the above examples assume. The majority of pensioners are married at 
some point in their retirement, so this could improve suitability for many people.

- It may still be advisable for some people in the high-risk category to save. For example, they could have a strong preference for smooth consumption over their lifetime.

- Conversely, it may not be advisable for people in the low-risk category to save, for example if they have high levels of debt. Levels of both secured and unsecured debt appear historically high and a sizeable minority of people carry over credit card balances from month to month.

- Whether contributions are affordable will depend on individual preferences on current expenditure and saving.

\section{Does suitability matter?}

If personal accounts are not suitable for everybody, this does not necessarily mean that individuals should not be auto-enrolled. But it does have important implications for what information is needed to help people make informed decisions about whether they should opt out.

Some of the factors that affect the suitability of personal accounts could be more problematic than others to incorporate into a system of generic information. Clearly, no one can predict with certainty all of their future life circumstances when making a savings decision. Some factors may be relatively straightforward to reflect in a system of generic information, such as current age, earnings and level of debt. Others may be more difficult, such as the affordability of contributions and likely future housing or marital status. These findings do suggest, however, that people will need very clear information to help them make informed decisions about whether they should stay in or opt out of personal accounts.

This is important for the success of policy. One issue is obviously the auto-enrolment of people in the high-risk groups. For these individuals, however, if they can be identified by broad characteristics (such as renting or age) information may be available to enable the right people to opt out.

More important could be the impact on people in the medium (and even low) risk groups, where it is less certain whether any particular individual will do well or not, as there are so many factors that will influence the outcome. While there is uncertainty as to the value of saving, this could remain a barrier to saving, working against inertia, and lead to people opting out, even if it would have been better for them to remain enrolled.

The Government has recognised that this is an issue, and the relevant Government department (the Department for Work and Pensions) is currently undertaking research, involving external stakeholders, to try and ascertain the potential importance of the problem and possible solutions. A number of suggestions have been put forward by interested organisations, ${ }^{2}$ and these are likely to be considered as part of this work.

\section{Will auto-enrolment increase pension saving?}

The second issue of concern about the policy of auto-enrolment is the possibility of employers 'levelling-down' provision, and the impact that this could have on total savings level for retirement. There are a number of different aspects that need to be considered:

- Will the reforms increase the number of people saving for retirement?

- Will the reforms increase the contributions to private pension saving?

- How will the reforms affect the existing market for pension saving?

\section{The number of people saving for retirement}

The reforms are likely to increase the number of people saving in a pension. Levels of opt-out remain uncertain, however, since the UK would only be the second country to introduce a national system of auto-enrolment. The reforms could result in at least 4-5 million new savers in work-based pension schemes and possibly up to 9 million (Table 1), depending on the rate at 
Table 1: New savers in work-based pension schemes under the reforms, in different participation scenarios

\begin{tabular}{llccc}
\hline & $\begin{array}{l}\text { Number in group } \\
\text { (DWP estimate) }\end{array}$ & $\begin{array}{l}\text { Optimistic scenario } \\
\text { (20\% opt-out) }\end{array}$ & $\begin{array}{l}\text { Central scenario } \\
\text { (33\% opt-out) }\end{array}$ & $\begin{array}{l}\text { Pessimistic scenario } \\
\text { (50-60\% opt-out) }\end{array}$ \\
\hline $\begin{array}{l}\text { Private sector employees who are not in a } \\
\text { work-based pension scheme and } \\
\text { who will be eligible for auto-enrolment } \\
\text { (in million) }\end{array}$ & 8.9 & 7.1 & 5.9 & $3.6-4.5$ \\
$\begin{array}{l}\text { Private sector employees who are not in } \\
\text { a work-based pension scheme and who } \\
\text { will not be eligible for auto-enrolment, } \\
\text { plus people who are economically } \\
\text { inactive or unemployed. These people } \\
\text { could voluntarily opt in to personal } \\
\text { accounts (in million) }\end{array}$ & 12.3 & 0.9 & 0.6 & 0.3 \\
$\begin{array}{l}\text { The self-employed, who could voluntarily } \\
\text { opt in to personal accounts (in million) }\end{array}$ & 2.8 & & \\
\hline $\begin{array}{l}\text { Total new savers in work-based pension schemes under the } \\
\text { reforms (in million) }\end{array}$ & 8.9 & 0.75 & 0.5 \\
\hline
\end{tabular}

aThese figures represent the DWP estimates as on November 2007. There have been subsequent estimates published (see DWP (2008) DWP (2008) Pensions Bill - Impact Assessment page 45, available from www.dwp.gov.uk/pensionsreform/) but these are not shown here as they would not be consistent with the PPI estimates contained in this table.

which people opt out of auto-enrolled provision. As we have seen, this in itself could be dependant on how individuals perceive the value of being auto-enrolled. Those who remain auto-enrolled will not all be new savers, since some of them will have previously been saving in a non-workbased pension or in non-pension forms of saving, but many would benefit from the proposed compulsory employer contribution.

The reforms may also benefit some people who were already saving in work-based pension schemes. The Government estimates that around 2 million private sector employees are currently saving in a work-based pension scheme with less than a 3 per cent employer contribution. These people could potentially have their employer contribution increased to 3 per cent of band earnings as a result of the reforms.

Higher participation in pension saving may mean that people are more likely to have an adequate income when they come to retire. As discussed above, however, there are also concerns that pension saving might not be suitable for everybody who is auto-enrolled. These concerns may mean that very high levels of participation may not necessarily be the best outcome for the reforms.

\section{Annual total pension contributions}

The future level of annual pension contributions is uncertain even without the Government's reform. Defined Benefit pension provision has already been declining in the private sector but there is not a consensus view among pension experts about the future of this type of provision. Contributions into Defined Contribution schemes, although growing, are also uncertain.

To analyse the possible outcomes of the reforms on annual pension contributions, this paper uses a baseline scenario for what could happen without reform. This shows annual total pension contributions falling from around $\delta_{4} 40 \mathrm{bn}$ in 2006 to around $\mathcal{E} 30$ bn by 2050 , relative to national average earnings (Figure 5).

The reforms will increase the costs of pension provision for most employers. This is because of the higher levels of participation in pension schemes that are likely to result from the requirement for employers to automatically enrol their employees into pension saving and because of the requirement to contribute at least 3 per cent for employees who remain opted in. Currently, only around 15 per cent of private sector employers offer schemes that are more 


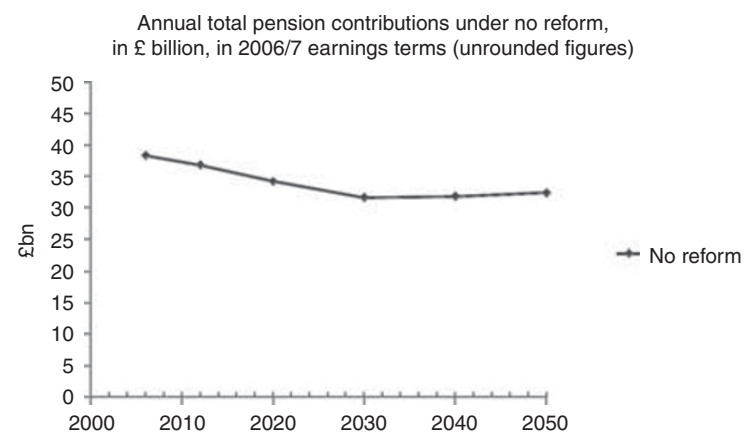

Figure 5: What could happen if there is no reform?

generous than the 3 per cent minimum contribution.

Employers may be able to pass on increased costs in a variety of ways, for example to consumers through higher prices, to workers through lower wage increases, or to shareholders or owners through lower profits. Employers who already contribute more than 3 per cent of band earnings could, however, decide to reduce their contributions as a way of meeting the cost of the reforms.

This paper uses four stylised scenarios to explore the possible implications of employers responding in different ways. Evidence on likely employer responses is limited and therefore the scenarios seek to illustrate the potential impact of a range of scenarios, rather than imply that any of the scenarios is more likely to occur. All of the scenarios are based on an overnight introduction of the reforms in 2012. In reality, the Government intends to phase in the compulsory employer contribution over a three-year period at the rate of 1 per cent each year. The scenarios are also based on the central scenario in Table 1 for individual reactions and therefore we can assume an opt-out rate of 33 per cent.

The reforms could increase annual total pension contributions, although employer responses will be very important in determining the total impact of the reforms on pension saving (Figure 6):

- If no employer decides to pass on the costs of the reforms by reducing their pension contributions (existing terms scenario), the

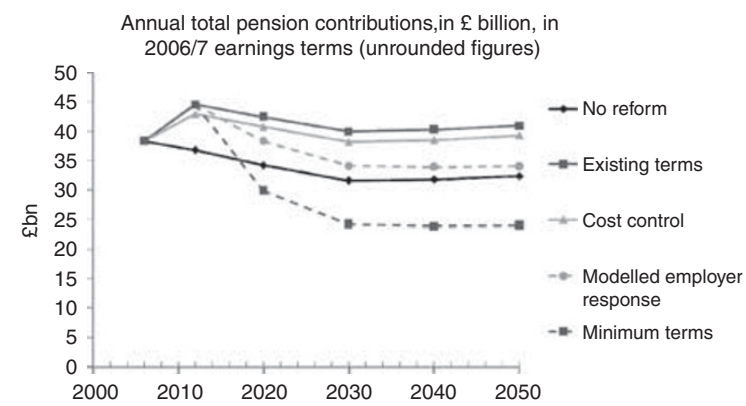

Figure 6: What if employers react in different ways?

reforms could increase annual total pension contributions (made by individuals, employers and the state combined) by around $\mathcal{E}_{10 \mathrm{bn}}$ in 2012 compared to without reform.

- Even if all of the employers who can reduce their pension contributions to hold their pension costs constant do so (cost control scenario), the reforms could still increase annual total pension contributions by around £.5bn in 2012 compared to without reform. This is because employers who do not already offer the minimum 3 per cent contribution to employees in work-based schemes will be compelled to do so under the reforms.

- If employers act in line with a survey of their likely responses (modelled employer response scenario), the reforms could increase annual total pension contributions by around $\mathcal{E}_{10 \mathrm{bn}}$ in 2012 compared to without reform. Some employers have, however, said they will close their existing schemes or reduce their pension contributions as a result of the reforms.

The reforms could still increase annual total pension contributions in 2050 but by less than $£ 2.5 \mathrm{bn}$ compared to without reform.

- It is important that employers continue to offer more than the 3 per cent minimum contribution. In the extreme situation where no employer offers more than the minimum (minimum terms scenario), annual total pension contributions could be $\mathcal{N}_{10 \mathrm{bn}}$ lower in 2050 than without reform.

Although annual total pension contributions would be higher than without reform under most 
of the scenarios, there would also be around 7 million more savers in work-based pension schemes.

Surveys of likely employer responses have been conducted, but they cannot predict with certainty how employers will act five years in advance of the reforms being introduced. Given the significant impact that employer behaviour will have on the outcome of the reforms, it will be important to continue to build the evidence base on employer responses in the period leading up to the introduction of the reforms. More recent Government research suggests that fewer employers may change provision than in the modelled employer response scenario used here, ${ }^{3}$ but full details of the research are not yet available.

\section{The shape of the pensions market}

Employers will have the choice of auto-enrolling their employees into an existing pension scheme or into a new national system of personal accounts. Their decisions will affect the shape of the pensions market and the split of the market between existing types of work-based pension provision and the new personal accounts (Figure 7).

If employers decide to auto-enrol their employees into existing schemes on existing terms, then the reforms could increase annual pension contributions to existing provision. This could benefit the current pensions industry. The bulk of the new contributions could, however, be made from employers who do not currently offer a work-based pension scheme, and their employees. If these employers decide to use personal accounts, then the majority of the increase in annual total pension contributions as a result of the reforms could be to personal accounts rather than to existing types of pension provision.

If employers choose to close their existing schemes as a result of the increased costs that they face from the reforms, then annual pension contributions into existing types of pension provision may be lower than without reform. This could lead to a reduction in the size of the

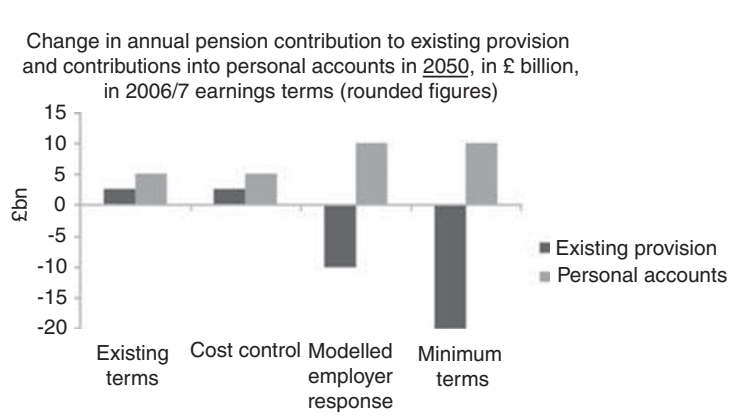

Figure 7: The reforms could change the shape of the pensions market

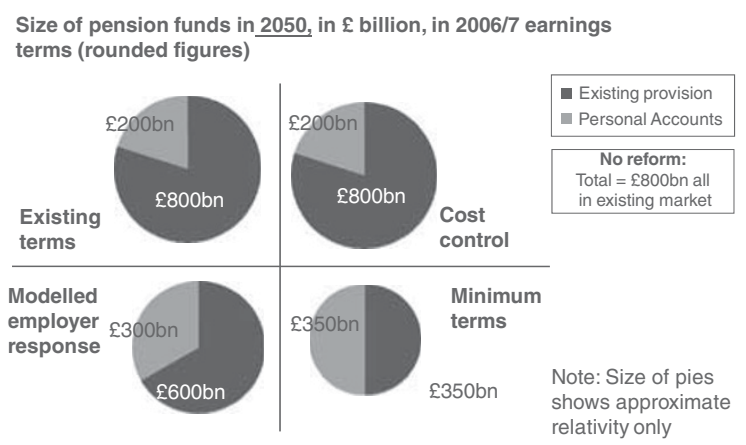

Figure 8: Funds in personal accounts could reach significant levels by 2050

existing pensions market compared to without the reforms.

It will be important for the success of the reforms that employers offer more than the 3 per cent minimum contribution. If employers only offer the 3 per cent minimum, then the aggregate size of pension funds under management in existing types of pension provision might still grow over time, but may not keep pace with growth in national average earnings.

The aggregate size of pension funds in personal accounts could grow to reach significant levels by 2050 (Figure 8). Organisations in the private sector will be used to manage these funds as well as administer them. This means that the reforms could provide a range of opportunities for the private sector.

\section{Does levelling-down matter?}

The Government has said that its reforms aim to increase the number of people saving for a pension and for personal accounts to complement, 
rather than compete with, existing good-quality pension provision.

There is the potential for the reforms to achieve both of these objectives. There can, however, be tensions between the two objectives. Some policy options may contribute positively to both but most involve a trade-off between the two.

This analysis shows that employers' responses to the introduction of the reforms will be critical in determining the overall impact that the reforms have on the level of pension saving. It is therefore important that the right balance is struck between encouraging new saving and protecting existing saving.

\section{Conclusions}

There is much that is positive in the reforms. The introduction of auto-enrolment should increase the number of people saving for their retirement. The interaction of the reforms with means-tested benefits and the risks of employers 'levellingdown' their pension contributions, however, both pose real challenges to the success of the reforms.

Overall, the jury is still out as to whether the Government's pension policy will deliver more people saving and more saving and better retirement incomes. There should be detailed consideration of further policy development to see if anything further is needed to give the announced reforms the best chance of meeting their objectives.

Disclaimer: This paper is intended as a contribution to the policy debate on personal accounts. It should not be relied on by individuals or their advisers as the basis for saving and investment decisions.

\section{Notes}

1 A work-based pension scheme in this context could be an occupational pension scheme, or a group personal or stakeholder pension. From 2012 personal accounts will also be an option.

2 For example, PPI (2007) 'Increasing the value of saving in Personal Accounts: Taking small pension pots as lump sums', A PPI report commissioned by the Equal Opportunities Commission, and PPI (2007) 'Increasing the value of saving in Personal Accounts: Rewarding modest amounts of pension saving', A PPI report commissioned by B\&CE Benefit Schemes, both available from www.pensionspolicyinstitute.org.uk.

3 High-level findings can be found in Grant Fitzpatrick Sinclair and Donovan (2008) 'Employers' attitudes and likely reactions to the personal account reforms 2007: A quantitative survey', available from www.dwp.gov.uk/pensionsreform/pdfs/Factsheetemployer-survey.pdf. 